\title{
Evaluation of phosphine genotoxicity at occupational levels of exposure in New South Wales, Australia
}

\author{
Anadergh Barbosa, Antonio M Bonin
}

\begin{abstract}
Phosphine has been claimed to cause chromosomal damage at exposures close to the current time weighted average exposure standard of $0.3 \mathrm{ppm}(0.4$ $\mathrm{mg} / \mathrm{m}^{3}$ ). The current study involved 31 phosphine fumigators and 21 controls during the high fumigation season. All were volunteers and were evaluated for genotoxicity variables, including micronuclei in peripheral blood lymphocytes and urine mutagenicity. In parallel, all fumigators and 17 controls were evaluated for full haematology, multiple biochemical analysis, whole blood organochlorines, and whole blood and serum cholinesterase activity. The results for micronuclei showed no significant differences between fumigators and controls, but detected a strong association between age and increased frequency of micronuclei. Measurement of urine mutagenicity did not show any significant difference between fumigators and controls, but did show increased excretion of mutagens in smokers. All haematological and biochemical variables were within normal ranges, except for some nonspecific changes in biochemistry. At monitored occupational exposures of $<2.4 \mathrm{ppm} / \mathrm{h}$ our results show no association between phosphine exposure and genotoxic or toxicological effects in fumigators.
\end{abstract}

(Occup Environ Med 1994;51:700-705)

Keywords: phosphine, micronucleus induction, urine mutagenicity

Department of Occupational Health, FHDF, Brasilia, Brazil

A Barbosa

Toxicology Unit, National Institute of Occupational Health and Safety, Worksafe Australia, Sydney,

Australia

A M Bonin

Correspondence to:

Dr AM Bonin, Toxicology

Unit, National Institute of

Occupational Health and

Safety, Worksafe Australia

GPO Box 58, Sydney,

New South Wales 2001,

Australia.

Accepted 6 June 1994 monary oedema, and death. ${ }^{3-5}$ Phosphine is a recognised poison to mammals, birds, and most insects and its toxicity and subsequent lethality is dependent on the duration and concentration of the exposure. ${ }^{6}$ Exposure by inhalation of phosphine seems to be the most effective route of absorption as it targets the whole respiratory tract, especially the lungs. ${ }^{5-7}$

Within the state of New South Wales, Australia, Grain Corp is the government organisation responsible for about $85 \%$ of the commercial grain stores (about 270 sites, 500 individual stores), with 31 fumigators being responsible for all phosphine fumigation. During a normal year, there are about 170-200 fumigations with phosphine that occur mainly during summer months (December-March). There are four main types of stores used by this corporation: sealed storages (gas-tight), bunker stores (temporary), SIROFLO stores (sealed base + open top), and unsealed non-SIROFLO stores.

In 1988, after the release of environmental health criteria on phosphine and selected metal phosphides, ${ }^{6}$ it became obvious that there was a lack of genotoxicity data on this compound. At the same time, phosphine was under review in the United States by the Environmental Protection Agency for renewal of the licence for its use in that country. Because of this lack of genotoxicity data, the Environmental Protection Agency demanded from the manufacturers of phosphine and metal phosphides a battery of tests for mutagenicity and carcinogenicity. These tests included an acute inhalation toxicity, an inhalation developmental toxicity, a 13 week inhalation toxicity, and Ames/Salmonella plate incorporation assay. ${ }^{7}$ In rats exposed to $10 \mathrm{ppm}$ for 3 days $(6 \mathrm{~h} /$ day $)$, there were decreased erythrocytes, lung congestion, and increased kidney weights with coagulative necrosis of the tubular epithelium in the outer cortex. Subchronically (6 h/day, 13 weeks), there was also a dose-related decrease in body weight gain at 1 and $3 \mathrm{ppm}$, with a $5 \%$ decrease in erythrocytes, haemoglobin, and packed cell volume found in the $3 \mathrm{ppm}$ group. Exposure of pregnant rats up to $4.9 \mathrm{ppm}$ showed no evidence of maternal or developmental toxicity.

In 1989, Garry et al published a study that associated occupational exposure to phosphine with increases in chromosomal aberrations, which may have implications for carcinogenicity. ${ }^{8}$ This generated the need to evaluate the occupational health and safety of workers handling this fumigant in Australia. Our study was therefore undertaken primarily to evaluate two biomarkers of genotoxicity 
(induction of micronuclei in peripheral lymphocytes and urine mutagenicity), as well as several other variables (full blood count, multiple biochemical analysis, whole blood organochlorines, serum and whole blood cholinesterase) on long term fumigators who were occupationally exposed to phosphine. Environmental monitoring was also performed to provide an indication of exposure.

\section{Materials and methods}

SUBJECT SELECTION

Fumigators $(\mathrm{n}=31$ ) working with phosphine (mean (range) $11.6(1.5-32)$ years) for the New South Wales Grain Corp and control subjects $(n=21)$ working on the same sites as grain handlers, mechanics, and clerks, volunteered for the study and were matched by sex, age, and smoking habit. All subjects gave signed consent for their participation in this investigation and the project was approved by the Sydney University Human Ethics Committee. Samples of blood and urine were collected over the period from February-April 1992. All subjects were given an approved personal health questionnaire by an experienced registered nurse, and details were obtained on chronic and acute illnesses, use of medication, diagnostic exposure to $x$ rays in the past 12 months, and exposure to potential mutagens. Subjects with a history of having medication or exposure to $x$ rays were subdivided into a separate group for evaluation of induction of micronuclei to ensure that such exposure was not a confounder.

\section{BLOOD AND URINE COLLECTION}

Blood and urine samples collected at the work sites were transported to the laboratory and processed within 12 hours. Blood was collected into six $10 \mathrm{ml}$ vacuum tubes (Greiner, three tubes with sodium heparin, two tubes with EDTA and one tube without additive). The tubes with sodium heparin were used for lymphocyte culture and determination of organochlorines and cholinesterase activity. Tubes with EDTA were used for full blood counts and tubes without preservatives for multiple biochemical analysis. Urine samples $(100 \mathrm{ml})$ were collected into $120 \mathrm{ml}$ sterile plastic bottles and transported in a container with ice. In the laboratory, the urine samples were stored at $-80^{\circ} \mathrm{C}$ until processing (up to four months) for urine mutagenicity.

\section{INDUCTION OF MICRONUCLEI}

Peripheral blood lymphocytes were separated from whole blood with a sterile gradient solution of Lymphoprep (sodium metrizoate, $9.6 \% \mathrm{w} / \mathrm{v}$; polysaccharide, $5.6 \% \mathrm{w} / \mathrm{v}$ ) with a mean (SD) density of $1.077(0.001) \mathrm{g} / \mathrm{ml}$ and osmolarity of 280 (15) mOsm (Nycomed Pharma AS, Oslo, Norway). The cytokinesisblock method as described by Fenech and Morley (1985) was used. ${ }^{9}$ Briefly, lymphocytes were cultured in Roswell Park Memorial Institute (RPMI)-1640 medium (Sigma
Chemicals, USA) supplemented with $15 \%$ foetal calf serum (FCS, Commonwealth Serum Laboratories, Australia), and stimulated to divide by addition of purified phytohaemagglutinin ( $2 \mu \mathrm{g} / \mathrm{ml}$, PHA HA-16, Wellcome Diagnostics, France), in a concentration of $0.75 \times 10^{6}$ cells $/ \mathrm{ml}$ of medium, in 24 well tissue culture plates (Linbro, Flow Laboratories). Two cultures for each subject were prepared, and cells were cultured at $37^{\circ} \mathrm{C}$ in a humidified atmosphere containing $5 \% \mathrm{CO}_{2}$ for 72 hours. After 44 hours of culture, Cytochalasin-B (Cyt-B, Sigma Chemicals, USA) was added at a concentration of $5 \mu \mathrm{g} / \mathrm{ml}$. After 72 hours of culture, cells were harvested and slides were prepared from $120 \mu \mathrm{l}$ of cell suspension (2/culture) with a cytospin Shandon, England; $(600 \mathrm{rpm}, 5$ min). The slides were stained with Diff-Quik Stain Set (modified Wright stain, Lab-Aids, cat 64851, Sydney, Australia), air dried for a minimum of two hours and mounted with cover slips, in Gurr XAM neutral medium (BDH Chemicals UK). A minimum of 1200 binucleated cells/subject were scored under oil immersion at $1000 \times$ magnification. All slides were scored blind. Micronuclei were scored in binucleated cells by the criteria. (a) diameter between $1 / 16$ to $1 / 3$ that of the main nuclei; (b) non-refractile; (c) not linked to the main nuclei; (d) morphologically identical to but smaller than the main nuclei.

URINE MUTAGENICITY

Amberlite XAD-2 resin (BDH Chemicals, UK, 20-50 mesh) was washed with acetone once, with methanol twice, and several times with distilled water. The resin was stored at $4^{\circ} \mathrm{C}$ and used as required. The urine samples were centrifuged for $10 \mathrm{~min}$ at $800 \mathrm{rpm}$ and the supernatant was passed through the chromatography column containing $2 \mathrm{ml}$ of XAD2 resin, at a rate of $2 \mathrm{ml} / \mathrm{min}$. Adsorbed mutagens were eluted with $6 \mathrm{ml}$ of acetone and collected in two $5 \mathrm{ml}$ glass tubes/sample. Samples were freeze-dried and the urine residue was reconstituted in $1.5 \mathrm{ml}$ of dimethyl sulphoxide. All media and solutions used in this assay were prepared as described by Maron and Ames. ${ }^{10}$ Two strains of Salmonella typhimurium (TA100 and TA98), with and without metabolic activation (S9 mix, male Sprague-Dawley rats treated with Aroclor 1254) were used with two different volumes of urine extract $(50$ and $100 \mu \mathrm{l})$. A total of 50 urine extracts were tested in five different batches $(10 / \mathrm{batch})$ with appropriate positive $(2.5 \mu \mathrm{g} /$ plate 2 -aminoanthracene and $2 \mu \mathrm{g} /$ plate sodium azide in the presence and absence of S9) and negative (dimethyl sulphoxide) controls.

\section{HAEMATOLOGY}

The following haematological variables were evaluated: haemoglobin, red cell counts, packed cell volume, mean cell volume, mean cell haemoglobin concentration, platelet counts, whole blood counts, differential white cell counts, and erythrocyte sedimentation rate. 


\section{BIOCHEMISTRY - SPECIAL AND MULTIPLE} ANALYSES

Two special tests were performed: whole blood organochlorines and serum and whole blood cholinesterase activity. Whole blood was screened for the presence of 13 organochlorines: hexachlorobenzene, Heptachlor epoxide, $\gamma$-chlordane, $a$-chlordane, Endrin, DDE, Lindane, Oxychlordane, Heptachlor, Aldrin, DDD, DDT, and Dieldrin, with a limit of detection of $1 \mu \mathrm{g} / \mathrm{l}$.

Multiple biochemical tests, conducted according to routine pathology laboratory analyses, were performed on blood samples from 31 fumigators and 17 controls (four samples of the control group were determined to be unsatisfactory for analysis) and included 19 variables: sodium, potassium, chloride, bicarbonate, urea, creatinine, uric acid, glucose, protein, albumin, total bilirubin, alkaline phosphatase, $\gamma$-glutamyl transpeptidase, serum aspartate aminotransferase (also known as serum glutamate oxaloacetate transaminase), serum alanine aminotransferase (also known as serum glutamate pyruvate transaminase), calcium, inorganic phosphate, cholesterol, and triglycerides.

\section{STATISTICAL ANALYSIS}

The Wilcoxon rank sum test was used to compare the frequencies of micronuclei between fumigations and controls, smokers and nonsmokers, and younger ( $<35 \mathrm{y})$ and older $\left(\geqslant 35\right.$ y) age groups. The $\chi^{2}$ test was used to compare the incidences of abnormal liver function tests between fumigators and controls. A one sided unpaired $t$ test was used to evaluate the significance of the mutagenic response in the urine mutagenicity assay.

\section{ENVIRONMENTAL MONITORING}

Phosphine concentration in the breathing zone of fumigators was recorded during 8 fumigations, with phosphine badges (Dräger, Germany) with detection limits ranging from 0.01 to $2.4 \mathrm{ppm} / \mathrm{h}$, depending on the duration of the measurement ( $30 \mathrm{~min}-8 \mathrm{~h}$ ). Just before phosphine release, each fumigator involved in a specific fumigation procedure placed a badge (in the appropriate housing) at the front of the collar as close as possible to the breathing zone. On the back of each badge was recorded the date, name of the user, fumigation technique and times of start and finish of the operation. During each fumigation that was monitored with badges, we also used phosphine tubes (Dräger, Germany), attached to a gas detector pump (Dräger) with detection

Table 1 Mean (SD) incidence of micronuclei in phosphine fumigators and controls exposed to medication and $x$ rays

\begin{tabular}{|c|c|c|c|c|c|c|c|c|c|}
\hline \multicolumn{5}{|c|}{ Fumigators } & \multicolumn{5}{|l|}{ Controls } \\
\hline $\begin{array}{l}M+ \\
(n=6)\end{array}$ & $\begin{array}{l}M- \\
(n=25)\end{array}$ & $\begin{array}{l}X+ \\
(n=2)\end{array}$ & $\begin{array}{l}X- \\
(n=29)\end{array}$ & $\begin{array}{l}F \\
(n=31)\end{array}$ & $\begin{array}{l}M+ \\
(n=4)\end{array}$ & $\begin{array}{l}M- \\
(n=17)\end{array}$ & $\begin{array}{l}X+ \\
(n=5)\end{array}$ & $\begin{array}{l}X- \\
(n=16)\end{array}$ & $\begin{array}{l}C \\
(n=21)\end{array}$ \\
\hline $\begin{array}{c}8 \cdot 2 \# \\
(4 \cdot 7)\end{array}$ & $\begin{array}{c}6 \cdot 6 \\
(4 \cdot 3)\end{array}$ & $\begin{array}{c}6 \cdot 7 \\
(3 \cdot 0)\end{array}$ & $\begin{array}{c}7 \cdot 0 \\
(4 \cdot 4)\end{array}$ & $\begin{array}{c}6.9 \\
(4 \cdot 4)\end{array}$ & $\begin{array}{c}6 \cdot 3 \\
(4 \cdot 0)\end{array}$ & $\begin{array}{c}7 \cdot 3 \\
(4 \cdot 0)\end{array}$ & $\begin{array}{c}5 \cdot 3 \\
(3 \cdot 6)\end{array}$ & $\begin{array}{c}7 \cdot 6 \\
(4 \cdot 0)\end{array}$ & $\begin{array}{c}7 \cdot 1 \\
(3 \cdot 9)\end{array}$ \\
\hline
\end{tabular}

$\mathrm{M}+=$ medicated; $\mathrm{M}-=$ non-medicated; $\mathrm{X}+=$ exposed to $x$ rays; $\mathrm{X}-=$ not exposed to $x$ rays $\mathrm{F}=$ total fumigators; $\mathrm{C}=$ total controls. limits of $0 \cdot 1$ to $40 \mathrm{ppm}$. These tubes served to overcome the limitations of the badges, which do not detect short term peak concentrations, and were used to obtain readings at a minimum of five and a maximum of 10 sampling points, based on the perceived relative risk at each point, for each fumigation.

When we used badges for monitoring, the manufacturer's recommendations for calculating the average phosphine concentration in ppm were followed, where the reading in $\mathrm{ppm} \times \mathrm{h}$, obtained from a printed colour comparison code on the badge, was divided by the exposure time $(\mathrm{h})$ :

$$
\mathrm{PH}_{3} \text { concentration in ppm }=\frac{\text { reading in ppm } \times \mathrm{h}}{\text { measuring period }(\mathrm{h})}
$$

\section{Results}

All fumigators and controls were assessed for history of illness, use of medication and exposure to $x$ rays in the past 12 months, as well as for diet and alcohol intake. No illnesses were recorded in fumigators or controls except for one fumigator who reported an occasional respiratory allergy. Of the 52 subjects, 10 received some form of medication, mainly antitetanus vaccine and vitamins and seven had been exposed to $x$ rays in the past 12 months. These two events were determined to have no confounding effect on the incidences of micronuclei in the respective groups (table 1)

The figure shows that the incidence of micronuclei in peripheral blood lymphocytes of 52 subjects divided into three comparative groups; (a) phosphine fumigators $(\mathrm{n}=31)$ and controls $(n=21)$; (b) smokers $(n=19)$ and non-smokers ( $n=33$ ), and (c) younger $(<35 \mathrm{y}, \mathrm{n}=16)$ and older $(\geqslant 35 \mathrm{y}, \mathrm{n}=36)$ subjects. In the first two groups, there were no significant differences in the incidence of micronuclei/1000 binucleated cells between fumigators $(6.9(4.5)$ and controls $(7 \cdot 1(4 \cdot 0)$ Wilcoxon, $P=0 \cdot 88)$, and smokers $(7 \cdot 2 \quad(3 \cdot 9)$ and non-smokers (6.8 (4.2)

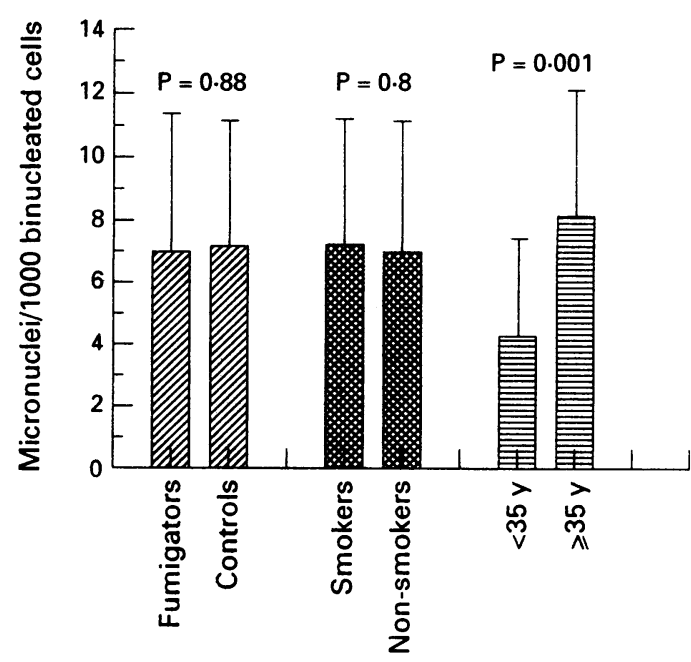

Frequency of micronuclei (mean (SD)) in fumigators $v$ controls, smokers $v$ non-smokers, and $<35 v \geqslant 35 y$ compared by Wilcoxon test. 
Table 2 Urine mutagenicity in fumigators and controls

\begin{tabular}{llllll}
\hline \multirow{2}{*}{$\begin{array}{l}\text { Degree of } \\
\text { mutagenicity }\end{array}$} & \multicolumn{2}{l}{ Fumigators $(n=27)$} & & \multicolumn{2}{l}{ Controls $(n=19)$} \\
\cline { 2 - 3 } \cline { 5 - 5 } & Smoker & Non-smoker & & Smoker & Non-smoker \\
\hline 0 & - & 12 & 1 & 8 \\
+ & 4 & 3 & - & 4 \\
++ & 1 & 2 & & - \\
+++ & 5 & - & 5 & 1 \\
Total & 10 & 17 & 6 & 13 \\
\hline
\end{tabular}

^Mutagenicity was assessed as follows: $0=$ no significant activity in either TA100 or TA98 \pm S9; $+=1.5 x$ background $(\mathrm{P}<0.05$; one-sided unpaired $t$-test $) ;++=2 x$ background $(\mathrm{P}<0.01) ; \quad+++=3 x$ background $(\mathrm{P}<0.001)$. The spontaneous revertant ranges for TA98 were $17-33(-S 9)$ and spontaneous revertant ranges for TA98 were 17-33 $(-S 9)$ and $(+S 9)$. The positive control, 2-aminoanthracene, consistently $(+S 9)$. The positive control, 2 -aminoanthracene, consistently
induced about 2500 revertants when applied at $2.5 \mu \mathrm{g} /$ plate in the presence of $S 9$, in all experiments.

Wilcoxon, $P=0 \cdot 8$ ). In the third group, however, there was an age related significant difference, with the younger subjects having a lower incidence of micronuclei/1000 binucleated cells $(4.5(3.4))$ than the older subjects $(8 \cdot 1(4 \cdot 0)$, Wilcoxon, $\mathrm{P}<0 \cdot 001)$.

Table 2 summarises the urine mutagenicity in Salmonella typhimurium strains TA100 and TA98 ( $\pm S 9$ ). Of a total of 27 fumigators, 15 (56\%) had mutagenic activity compared with $10(53 \%)$ out of 19 control subjects. This activity seemed to be unrelated to phosphine fumigation but there was a relation with smoking: $100 \%$ of the fumigators and $83 \%$ of the controls who smoked excreted mutagenic urine.

Haematological tests on 31 fumigators and four controls were consistent with normal values, but there was a slightly raised packed cell volume in one fumigator and one control subject. Whole blood and serum cholinesterase were within the normal range for all subjects $(3 \cdot 6-6 \cdot 3 \mathrm{KU} / 1$ and $1 \cdot 0-4 \cdot 3 \mathrm{KU} / \mathrm{l})$ and concentrations of organochlorines were within acceptable limits (Work Cover, New South Wales).

Table 3 Percentage of fumigators and controls with raised liver function variables

\begin{tabular}{lccclc}
\hline $\begin{array}{l}\text { Liver } \\
\text { variables }\end{array}$ & $\begin{array}{l}\text { Normal } \\
\text { range }\end{array}$ & $\begin{array}{l}\text { Fumigators } \\
n=31(\%)\end{array}$ & Range & $\begin{array}{l}\text { Controls } \\
n=17(\%)\end{array}$ & Range \\
\hline Total bilirubin & $3-18 \mu \mathrm{mol} / 1$ & $2(6 \cdot 5)$ & $19-21$ & 0 & - \\
Alkaline phosphatase & $30-120 \mathrm{U} / 1$ & $1(3 \cdot 2)$ & 173 & $1(5 \cdot 9)$ & 167 \\
$\gamma-$-Glutamyl transpeptidase & $0-50 \mathrm{U} / 1$ & $11(35 \cdot 54)$ & $53-163$ & $3(17 \cdot 6)$ & $52-117$ \\
Alanine aminotransferase & $0-45 \mathrm{U} / 1$ & $8(25 \cdot 8)$ & $47-156$ & $2(11 \cdot 7)$ & $48-71$ \\
Aspartate aminotransferase & $0-45 \mathrm{U} / 1$ & $1(3 \cdot 2)$ & 47 & 0 & - \\
$\geqslant 1$ Variable & & $17(54 \cdot 8)$ & - & $6(35 \cdot 3)$ & - \\
\hline
\end{tabular}

^Subjects with one or more raised liver function variables.

Table 4 Environmental monitoring of phosphine fumigation sites

\begin{tabular}{|c|c|c|c|c|c|c|}
\hline \multirow{2}{*}{$\begin{array}{l}\text { Date } \\
\text { of } \\
\text { fumigation }\end{array}$} & \multirow{2}{*}{$\begin{array}{l}\text { Type } \\
\text { of } \\
\text { fumigation }\end{array}$} & \multirow{2}{*}{$\begin{array}{l}\text { Type } \\
\text { of } \\
\text { store }\end{array}$} & \multicolumn{3}{|c|}{ Individual measurements ${ }^{\star}$} & \multirow{2}{*}{$\begin{array}{l}\text { Duration } \\
\text { (h) }\end{array}$} \\
\hline & & & (A) & (B) & (C) & \\
\hline $11 / 2 / 92$ & Gas & Sealed & $1 \cdot 6$ & $2 \cdot 4$ & $<0.1$ & 1 \\
\hline $02 / 4 / 92$ & AIP pellets & Bunker & $<0.1 \dagger$ & $<0.1+$ & $<0.1 \dagger$ & $0 \cdot 2$ \\
\hline $02 / 4 / 92$ & SIROFLO & Unsealed & $<0.1$ & $<0.1$ & $<0.1$ & 0.8 \\
\hline $13 / 2 / 93$ & Blankets & Sealed & 0.4 & $0 \cdot 1$ & - & 1 \\
\hline $14 / 2 / 93$ & Blankets & Bunker & $<0.1$ & 0.4 & 0.8 & 1 \\
\hline $16 / 2 / 93$ & AIP tablets $\ddagger$ & Unsealed & 0.8 & $1 \cdot 2$ & $1 \cdot 2$ & 2 \\
\hline $01 / 6 / 93$ & SIROFLO & Unsealed & $<0.1$ & $<0.1$ & $<0.1$ & 1 \\
\hline $01 / 6 / 93$ & SIROFLO & Sealed & $<0.1$ & $<0.1$ & $<0.1$ & 0.7 \\
\hline
\end{tabular}

$\star=$ Badges, $\mathrm{ppm} / \mathrm{h} ; \dagger=$ fumigation time $<30 \mathrm{~min}$ was unsuitable for monitoring with phosphin badges (measurements with phosphine tubes showed values $<0.4 \mathrm{ppm}$ for no longer than 10 $\min ) ; \ddagger=$ monitoring with phosphine tubes showed values $<2.4 \mathrm{ppm}$ during the last hour of the procedure.
Table 3 shows biochemical results from fumigators and controls. Overall, $54 \cdot 8 \%$ of fumigators and $35 \cdot 3 \%$ of controls had one or more increased liver function variables. Furthermore, $51 \cdot 6 \%$ of fumigators had raised cholesterol (range $5 \cdot 7-7 \cdot 1 \mathrm{mmol} / \mathrm{l}$ ) $v 47 \%$ of controls (range $5 \cdot 7-6 \cdot 4 \mathrm{mmol} / \mathrm{l}$ ); $45 \cdot 2 \%$ of fumigators had raised triglycerides (range $2 \cdot 2-4 \cdot 3 \mathrm{mmol} / \mathrm{l}$ ) $v 52 \cdot 9 \%$ of controls (range $2 \cdot 2-3.8 \mathrm{mmol} / \mathrm{l}) ; 19 \cdot 3 \%$ of fumigators had raised glucose (range $3 \cdot 1-9.6 \mathrm{mmol} / \mathrm{l}$ ) $v 5.9 \%$ of controls (range $3 \cdot 1-6.0 \mathrm{mmol} / 1$ ) $; 12.9 \%$ of fumigators had raised urea (range 2.5-3.2 $\mathrm{mmol} / \mathrm{l}) v 5.9 \%$ of controls $(2.7 \mathrm{mmol} / \mathrm{l})$; $53.1 \%$ of fumigators had altered concentrations of some of the liver function variables $(\gamma$-glutamyl transpeptidase, serum aspartate aminotransferase, serum alanine aminotransferase, total bilirubin, alkaline phosphatase) $v$ $35.3 \%$ of controls. All other variables were within the normal range.

The results of environmental monitoring showed phosphine exposures that varied in concentration and duration (table 4), depending on the techniques used. In the three SIROFLO fumigations monitored, no phosphine was detected in the work environment, whereas fumigation with blankets, either in sealed stores or bunkers, showed detectable concentrations varying from $0 \cdot 1$ to $0.8 \mathrm{ppm}$ over a maximum period of one hour. In the unsealed store where fumigation was with AlP (aluminium phosphide) tablets by the "probe and sheet" method, phosphine badges (detection limits of 0.01 to $2.4 \mathrm{ppm}$ ) worn by three fumigators showed results of $0 \cdot 8,1 \cdot 2$, and $1 \cdot 2$ $\mathrm{ppm} / \mathrm{h}$. This technique took two hours to be performed. During the last hour of the procedure, concomitant monitoring with Dräger tubes (range $0 \cdot 1$ to $40 \mathrm{ppm}$ ) showed a mean (SD) concentration of $2(0.5) \mathrm{ppm}$.

\section{Discussion}

Phosphine has been implicated in the induction of chromosomal aberrations in phosphine fumigators at occupational exposures of $0.1-0.9 \mathrm{mg} / \mathrm{m}^{3}(0.07-0.63 \mathrm{ppm})$ in open air and $0.4-5.8 \mathrm{mg} / \mathrm{m}^{3}(0.28-4.11 \mathrm{ppm})$ in enclosed spaces. ${ }^{8}$ Analyses of chromosomal aberrations and micronuclei show that they are strongly associated, especially when the damage is due to breaks or aneuploidy. Formation of micronuclei is an indirect indicator of chromosomal damage and is comparable in sensitivity to metaphase analysis. ${ }^{11}$ The results of the incidences of micronuclei in phosphine fumigators in this study do not associate occupational exposure to phosphine with any clastogenic or aneugenic effect in lymphocytes. When data from fumigators and controls are pooled and analysed by age (< 35 and $\geqslant 35$ ), the increase in frequency of micronuclei seen in the older group is significant (Wilcoxon, $\mathbf{P}<0.001$ ) compared with the younger group. These results are in accordance with several other reports on increased DNA damage with age. ${ }^{12} 13$

Urine mutagenicity has been successfully applied as a screening technique to detect 
occupational exposure to mutagenic substances $^{1415}$ and dietary mutagens. ${ }^{16}$ Our results showed no significant difference in excretion of mutagens in fumigators and controls. It is important, however, to consider that due to logistical limitations, some of the urine samples could not be collected in the 24 hour period after fumigation-neither were there pooled 24 hour specimens, as recommended by Falck et al. ${ }^{14}$ Nevertheless, when data from all subjects (fumigators and controls) were analysed for the influence of smoking habits, it was clear that cigarette smoking increased urine mutagenicity, where $100 \%$ of fumigators who smoked had mutagenic urine compared with $29 \%$ of fumigators who did not smoke. It is also important to note that none of the fumigators who did not smoke had more than double the background mutation frequency whereas $50 \%$ of the fumigators who smoked trebled their mutation frequency, compared with the spontaneous background. Of the control subjects who smoked, $83 \%$ had mutagenic urine compared with $38 \%$ of controls who did not smoke. Furthermore, $100 \%$ of the controls who smoked and had mutagenic urine had a threefold increase, whereas $80 \%$ of the controls who did not smoke but had mutagenic urine had only a 1.5 -fold increase over background. This is consistent with the well documented influence of cigarette smoking on urine mutagenicity. ${ }^{14} 17$

The results of multiple biochemical analyses showed a variety of mild changes that could be associated with phosphine exposure. Serum cholinesterase activity was within the normal range for all subjects investigated in our study. Inhibition of cholinesterase activity has been found in acute phosphine poisoning where ingestion of aluminium phosphide tablets resulted in a high percentage of cases with decreased serum cholinesterase activity. ${ }^{3} 18$ On the other hand, 31 crew members of a grain freighter accidentally exposed.through inhalation showed normal concentrations of serum cholinesterase activity except for one subject. ${ }^{19}$ Our results do not show any association between inhibition of serum cholinesterase activity and phosphine exposure. Recently, Potter et al reported a significant decrease in anticholinesterase and (butyryl)cholinesterase activity in phosphine fumigators, and suggested a dose-related effect. ${ }^{20}$ We think, however, that some of the previously reported levels of exposure ${ }^{128}$ were probably higher than most of the levels currently found, due to the poorer work practices and technology that existed at that time. Nevertheless, our data show that at the current occupational levels of exposure encountered in the New South Wales stores, such an effect is not present.

Increases in serum transaminases and decreases in serum cholinesterase activity have been found in oral phosphine poisoning. ${ }^{3}$ Although such exposure would be expected to cause liver damage with a subsequent increase in serum transaminase concentrations, the effect on transaminase concentrations at a low level of chronic exposure still needs further investigation. In our study, $29 \%$ of fumigators had raised transaminases (serum aspartate aminotransferase, serum alanine aminotransferase) compared with $11 \cdot 7 \%$ of controls, which may be associated and consistent with liver damage due to phosphine toxicity. ${ }^{6}$ An increase in $\gamma$-glutamyl transpeptidase that occurred in $34.4 \%$ of fumigators compared with $17.6 \%$ of controls, may be partly explained by alcohol consumption, where $77 \cdot 4 \%$ of the fumigators and $61.9 \%$ of controls reported a medium (216-432 g/week) to high (450-648 g/week) alcohol intake. Cholesterol and triglycerides were raised in fumigators $(51.6 \%$ and $45.2 \%$, respectively) as well as in controls $(47 \%$ and $52.9 \%$, respectively). This suggests that diet (data not shown) is a significant contributor to these increases. Considering liver function in general, $53.1 \%$ of fumigators had an increase of one or more variables compared with $35.3 \%$ of controls. Although this difference was not significant $\left(\chi^{2}=1.68, \quad P>0.19\right)$, further investigations are needed to evaluate if there are any possible biological implications. The haematological variables we evaluated were within the normal range, consistent with other findings in humans, ${ }^{5}$ but in contrast to animal studies. $^{7}$

In spite of our small sample, the results of environmental monitoring showed that the exposures experienced by the fumigators in this study are far lower than those reported previously. ${ }^{128}$ Although phosphine is a potent poison, our results show that it is possible to keep exposure to this fumigant at levels that do not present detectable health risks as measured by the genotoxicity biomarkers used in this study. Furthermore, monitored concentrations of phosphine in the work environment showed that the SIROFLO fumigation technique resulted in the lowest occupational exposures whereas the probe and sheet method resulted in the highest. The probe and sheet method is being phased out but the SIROFLO technique is increasing in use, currently accounting for about $70 \%$ of all fumigations conducted by Grain Corp. Under current occupational exposures encountered in grain stores in New South Wales, the concentration of phosphine as measured by us ( $<$ $2 \cdot 4 \mathrm{ppm}$ over a period of one hour) has not been shown to elicit any detectable adverse effects, as measured by induction of micronuclei, urine mutagenicity, and standard haematological analysis.

We thank Dr Robert Baker for his significant input during the initial phase of this project. We are also indebted to Mr Carlos Corvalan for assisting in the statistical analyses of the data, Dr Neill Stacey for his participation during part of this work, and Dr Grahame Budd for critical evaluation of the manuscript. This research was supported by Grain Research and Development Corporation (GRDC), the University of Sydney, Conselho Nacional de Desenvolvimento Cientifico e Tecnologico (CNPq-Brazil), and the New South Wales Grain Corporation.

The views expressed in this article are those of the authors and do not necessarily reflect those of the National Occupational Health and Safety Commission. 
1 Jones AT, Jones RC, Longley EO. Environmental and clinical aspects of bulk wheat fumigation with alu-
minium phosphide. Am Ind Hyg Assoc $\mathscr{f} 1964 ; 25: 376-9$.

2 Zaebst DD, Blade LM, Burroughs GE, Morrelli-Schroth P, Woodfin WJ. Phosphine exposure in grain elevators
, during fumigation with aluminum phosphide. Applied Industrial Hygiene 1988;3:146-54.

3 Singh RB, Rastogi SS, Singh DS. Cardiovascular manifestations of aluminum phosphide intoxication. $\mathcal{f} A s s o c$ Physicians India 1989;37:590-2.

4 Chugh SN, Singhal HR, Girdhar NK, Arora BB, Malhotra KC. Aluminium phosphide poisoning: Analysis of 228 cases. 7 Assoc Physicians India 1989;37:28-9.

5 Chungh SN, Ram S, Mehta LK, Arora BB, Malhotra KC. Adult respiratory distress syndrome following Adult respiratory distress syndrome following Assoc Physicians India 1989;37:271-2.

6 World Health Organization. Phosphine and selected metal phosphides. International programme on chemical safety. Geneva: WHO, 1988. (Environmental health criteria No 73.)

7 Newton PE, Schroeder RE, Sullivan JB, Busey WM, Banas DA. Inhalation toxicity of phosphine in the rat: acute, subchronic, and developmental. Inhalational Toxicology 1993;5:223-39.

8 Garry VF, Griffith J, Danzl TJ, Nelson RL, Whorton E, Krueger LA, Cervenka J. Human genotoxicity: pesticide applicators and phosphine. Science 1989;246:251-5.

9 Fenech M, Morley AA. Measurement of micronuclei in lymphocytes. Mutat Res 1985;147:29-36.

10 Maron DM, Ames BN. Revised methods for the Salmonella mutagenicity test. Mutat Res 1983;113: 173-215.

11 Klisech U, Danford N, Adler D. Micronucleus test and bone-marrow chromosome analysis. A comparison of 2 methods in vivo for evaluating chemically induced chromosomal alterations. Mutat Res 1981;80:21-32.

12 Fenech M, Morley AA. The effect of donor age on spontaneous and induced micronuclei. Mutat Res 1985;148: 99-105.

13 Richard F, Aurias A, Couturier J, Dutrillaux A, FlüryHérard A, Gerbault-Sereau M, et al. Aneuploidy in human lymphocytes: an extensive study of eight individuals of various ages. Mutat Res 1993;295:71-80.

14 Falck K, Grohn P, Sorsa M, Vainio H, Heinonen E, Holsti LR. Mutagenicity in urine of nurses handling cytostic drugs. Lancet $1979 ; \mathrm{i}: 1250-1$.

15 Mielzynska $D$, Snit $M$. Urine mutagenicity in workers directly employed in coke production. Polish fournal of Occupational Medicine 1992;5:363-71.

16 Poyen D, De Méo MP, Botta A, Gouvernet J, Duménil G. Handling of cytostatic drugs and urine mutagenesis. Int Handling of cytostatic drugs and urine muta

17 Baker RSU, Darnton-Hill I, Bonin AM, Arlauskas A, Braithwaite C, Wootton M, Truswell AS. Urine mutagenicity as an indicator of exposure to dietary mutagens formed during cooking of foods. Environ Health Perspect 1986;67:147-52.

18 Rastori P, Raman R, Shanker A. Serum cholinesterase activity and brain tissue (acetyl cholinesterase activity) in aluminium phosphide poisoning. $\mathcal{F}$ Assoc Physicians India 1989;37:28-9.

19 Wilson R, Lovejoy FH, Jaeger RJ, Landrigan PL. Acute phosphine poisoning abroad a grain freighter. phosphine poisoning abroad a grain freighter. 1980;244:148-50.

20 Potter WT, Garry VF, Kelly JT, Tarone R, Griffith J, Nelson RL. Radiometric assay of red blood cell and plasma cholinesterase in pesticide appliers from Minnesota. Toxicol Appl Pharmacol 1993;119:150-5.

\section{Rejected manuscripts}

From February 1994, authors whose submitted articles are rejected will be advised of the decision and one copy of the article, together with any reviewers' comments, will be returned to them. The fournal will destroy remaining copies of the article but correspondence and reviewers' comments will be kept. 